\title{
A Cross-Sectional Study of Self-Rated Health among Older Adults: Association with Drinking Profiles and Other Determinants of Health
}

\author{
Pascale Audrey Moriconi and Louise Nadeau \\ Department of Psychology, Université de Montréal, CP 6128, Succursale Centre-Ville, Montréal, QC, Canada H3C 3J7 \\ Correspondence should be addressed to Pascale Audrey Moriconi; pascale.audrey.moriconi@gmail.com
}

Received 30 September 2015; Accepted 9 December 2015

Academic Editor: Abebaw Yohannes

Copyright (C) 2015 P. A. Moriconi and L. Nadeau. This is an open access article distributed under the Creative Commons Attribution License, which permits unrestricted use, distribution, and reproduction in any medium, provided the original work is properly cited.

\begin{abstract}
This study compares the relationship between drinking profiles and self-rated health with and without adjusting for other determinants of health among a sample of older adults from the general population. Respondents were 1,494 men and 2,176 women aged between 55 and 74 from the GENACIS Canadian survey. The dependent variable was self-rated health, an individual's perception of his or her own general health, a measure used as a proxy for health status. The independent variables were drinking profiles (types of drinkers and nondrinkers) as well as other demographic, psychosocial, and health-related variables (control variables). After adjustment for other determinants of health, regression analyses showed that (1) frequent/moderate drinkers were more likely to have a better self-rated health compared with nondrinkers (lifetime abstainers and former drinkers) and (2) selfrated health did not differ significantly between frequent/moderate drinkers and other types of drinkers (frequent/nonmoderate and infrequent drinkers). Our results suggest that drinking is related to a better self-rated health compared with nondrinking regardless of the drinking profile. Drinking and healthy lifestyle guidelines specific to older adults should be studied, discussed, and integrated into public health practices.
\end{abstract}

\section{Introduction}

Population aging is a worldwide phenomenon, caused mainly by an increase in life expectancy combined with a decrease in fertility rates [1]. Evidence suggests that the number of individuals aged 60 years and older will exceed the number of children by 2047. This major shift has important repercussions on health, health systems, and budgets and has consequently brought global attention to health-related domains.

In alcohol research, the topic of older adults' health has traditionally been controversial. On one hand, older adults are more likely to experience adverse effects of alcohol (due to higher and longer-lasting blood alcohol concentrations caused by normal physiological changes with aging), to suffer from chronic diseases and to use medication that may interact with alcohol [2-4]. On the other hand, older adults are more likely to benefit from moderate levels of alcohol consumption. The protective effect of moderate drinking on all-cause mortality and cardiovascular morbidity and mortality [5-10] has been shown to increase in middle-aged and older adults [11-15]. A J-shaped relationship has been found, where abstainers have a higher mortality risk than moderate drinkers, whereas excessive (heavy) drinkers have a higher mortality risk than both abstainers and moderate drinkers $[6,9,10,16]$. A meta-analysis showed the lowest risk of coronary heart disease mortality among those who reported 1-2 drinks per day; however, for stroke mortality, the lowest risk occurred among those who reported 1 drink or fewer per day [10].

These results have been debated because of two main methodological limitations: (1) the composition of the abstainers' group to which moderate drinkers are generally compared and (2) the potential impact of confounding factors. First, the abstainers' group generally includes lifetime abstainers, former drinkers, and, in some studies, infrequent (and usually light) drinkers. However, since former and infrequent drinkers may stop or reduce their drinking because of 
health-related issues [17-22], health status possibly dictates drinking habits more than drinking habits affect health status. Thus, the potential benefits of moderate drinking may be artificially increased [23].

Secondly, critics have made the problem of potential confounding factors explicit; that is, the protective effect of moderate drinking could be partially explained by other determinants of health which are likely to be associated with a reduction in the risk of cardiovascular morbidity and mortality, such as education, socioeconomic and marital status, social network, psychological health, and other health-related behaviours (e.g., diet, nonsmoking habits, and exercising) [17, 18, 20, 21, 24-27]. For example, former drinkers (defined as those who did not drink in the past year) and long-term abstainers are more likely to be less educated, to be of a lower socioeconomic status than drinkers [18, 27-31], and to receive less social support $[27,32]$. These characteristics are in turn related to higher mortality risks [33]. In addition, Naimi and colleagues [26] found that, among US adults from the general population, nondrinkers (defined as those who did not drink during the past 30 days) were more likely to have characteristics associated with increased cardiovascular mortality, such as reporting lower overall physical activity level, being overweight, having less access to health services, presenting comorbid health issues (diabetes and hypertension) and poorer general health status, and having a higher risk of developing cardiovascular diseases.

Subsequent studies have therefore either excluded former drinkers from the abstainer category or analyzed them separately. Yet lifetime abstainers remained at higher morbidity and mortality risk compared with moderate drinkers [23, 34]. They also controlled for confounding factors and have persisted in finding a significant relationship between moderate drinking and a lower risk for cardiovascular morbidity and mortality $[8,16]$. Currently, the evidence indicates that moderate drinking is associated with better cardiovascular health, but the relationship may still be exacerbated by other determinants of health.

The objectives of the study are (1) to assess the relationship between older adults' drinking profiles and self-rated health, more specifically to compare moderate drinkers with other types of drinkers and nondrinkers, and (2) to assess whether and how this relationship is modified by other determinants of health including demographic, psychosocial, and healthrelated factors. Drinking profiles are expected to be significantly associated with self-rated health, with moderate drinkers perceiving themselves as healthier than other types of drinkers and nondrinkers. Differences between moderate drinkers and other types of drinkers and nondrinkers are expected to disappear when considering demographic, psychosocial, and health-related factors.

\section{Materials and Methods}

2.1. Participants and Procedure. This study is part of the international, collaborative GENACIS project (GENder, Alcohol, and Culture: an International Study) that emphasizes topics including alcohol consumption, beverage preferences, drinking consequences and contexts, reasons for drinking and abstaining, social networks, and psychological and physical health. In Canada, the survey was approved by the Centre for Addiction and Mental Health Research Ethics Board. It is based on a representative sample of 14,067 adults aged between 18 and 76 years from the 10 provinces [35]. A two-stage sampling method was used: households were first selected using random-digit dialing (RDD) and in instances where there were more than one adult in the household, the adult chosen as the survey respondent was the one whose birthday followed the survey date most closely. The survey was conducted between January 2004 and March 2005 with computer-assisted telephone interviewing (CATI). Respondents were interviewed in the Canadian official language of their choice (French or English). On average, interview duration was 25.64 minutes $(\mathrm{SD}=7.46)$. The overall response rate was $52.8 \%$. The present study included a subsample of older adults between the ages of 55 and $74(n=3,670)$ with a total of 1,494 men and 2,176 women. Only a small number of respondents were 75 or older, so it was decided not to include them in the analyses. Twenty-one male and 36 female respondents were excluded from the analyses because of discrepancies in their answers (i.e., interitem). The final subsample included 1,473 men and 2,140 women.

\subsection{Measures}

2.2.1. Dependent Variable. Previous research has shown a strong association between self-rated health, a person's evaluation of his or her own general health, and other direct and indirect measures of health including health assessments performed by general physicians [36-40]. In this study, selfrated health is used as a proxy for actual health status. Selfrated health was assessed with the following question: "In general, compared to others your age, how has your physical health been in the last 12 months: excellent, very good, good, fair, or poor?" On a five-point scale, answers ranged from excellent (1) to poor (5).

\subsubsection{Independent Variables}

(1) Drinking Measures. Among measures of alcohol consumption, current drinking was assessed with the following question: "Did you consume any alcohol beverages such as wine, beer, hard liquor, sherry, coolers, or any other beverages containing alcohol during the last 12 months?" To distinguish between lifetime abstainers and former drinkers, we used two specific questions: "Have you ever drunk alcohol?" ( $0=$ no or $1=$ yes) and "How old were you when you first drank alcohol, more than just a sip or a taste?" Lifetime abstainers are those who never drank alcohol and who never drank alcohol more than just a sip or a taste. Former drinkers are those who have drunk alcohol prior to last 12 months and who drank alcohol more than just a sip or a taste.

We used three alcohol consumption dimensions to build our drinking profiles typology: the usual frequency of drinking, the usual frequency of having five standard drinks or more per drinking day (binge drinking), and the usual quantity of drinking per drinking day. For the usual frequency of drinking and binge drinking, respondents were asked the 
following question: "During the last 12 months, how often did you usually have any kind of drink containing alcohol (how often did you usually have five drinks or more on a single day)?" Possible responses included the following: every day, 5-6 days a week, 3-4 days a week, 1-2 days a week, 1-3 days a month, less than once a month, or never. The first three categories were merged into one category (3 days a week or more) due to the small number of respondents drinking and binge drinking daily. For the usual quantity per drinking day, respondents were asked the following: "One drink means one $12 \mathrm{oz}$. of regular beer, $5 \mathrm{oz}$. of wine, $3 \mathrm{oz}$. of port, sherry or vermouth, one-and-a-half oz. of hard liquor or liquor, or one $12 \mathrm{oz}$. of cooler. In the past 12 months, on those days when you had any kind of beverage containing alcohol, how many drinks did you usually have?" Answers ranged from 0.8 (light beer) to 28 drinks per day in this subsample and were recoded into a three-category variable: (1) 1-2 (including 0.8 ) drinks per drinking day, (2) 3-4 drinks per drinking day, and (3) 5 drinks or more per drinking day.

To categorize drinkers, we used cross-observations of the three alcohol consumption dimensions. In addition to the lifetime abstainers and former drinkers, the final drinking profiles typology included three categories of drinkers: (1) frequent and moderate drinkers, (2) frequent and nonmoderate drinkers, and (3) infrequent drinkers. Frequent and moderate drinkers were those who usually drank once a week or more, who drank 1 or 2 standard drinks per drinking day, and who binge drank less than once a month (including never in the past 12 months). For the frequent and nonmoderate drinkers, two profiles were observed: (1) drinkers who drank once a week or more and who drank 3 standard drinks or more per drinking day (no matter the binge drinking frequency) and (2) drinkers who drank 1 or 2 standard drinks per drinking day and binge drank once a month or more. The infrequent drinkers are those who usually drink less than once a week. Thirty male and 19 female respondents were excluded because they presented missing values on one or more of the three alcohol consumption dimensions, which made their categorization impossible.

(2) Demographic Measures. Demographic measures include gender, age, marital status, level of education, and employment status. The income measure was excluded because the number of missing values was disproportionately high. Age was treated as a continuous variable ranging from 55 to 74 . Marital status was divided into three categories: married/partnered, divorced/separated/widowed, and single/never married. Level of education was a four-category variable ranging from 1 (less than secondary education) to 4 (university degree). Employment status included the following three categories: working for pay, retired, and other. The "other" category referred to those going to school, caring for family, on disability, or unemployed.

(3) Psychosocial Measures. For the psychosocial measures, we assessed for the availability of at least one person with whom they felt comfortable talking to (a confidant) by asking the following: "(Apart from your spouse/partner/romantic partner), is there someone that you feel confident that you can talk to about an important personal problem?" Membership in any voluntary organizations or associations was assessed with the following: "Are you a member of any voluntary organizations or associations such as school groups, church social groups, community centers, ethnic associations or social, civic or fraternal clubs?" We evaluated respondents' perception of psychological health with the question: "How would you describe your overall emotional and mental health? In general, over the last 12 months, has it been excellent, very good, good, fair or poor?" $(1=$ excellent to 5 $=$ poor $)$.

(4) Health-Related Measures. Body mass index (BMI) was derived by dividing respondents' weight (kilograms) by height squared (meters). Weight and height were selfreported. We asked respondents the following: "Can you tell me how tall you are without shoes?" and "How much do you weight?" Scores were recoded into a four-category BMI variable based on the WHO classification [41]: (1) underweight (BMI less than 18.5), (2) normal weight (18.5 to 24.9), (3) overweight (25 to 29.9), and (4) obese (30 and above). Cigarette smoking status was assessed by asking two questions: "Have you ever been a cigarette smoker?" and "Have you smoked cigarettes during the past 12 months?" Cigarette smoking status was then recoded into a threecategory variable: (0) never smoked, (1) smoked prior to the past 12 months, and (2) smoked within the past 12 months. To assess psychotropic drug use, we asked the following: (1) "In the past 12 months, did you take tranquilizers such as Valium or Ativan?", (2) "In the past 12 months, did you take antidepressants such as Prozac, Paxil or Effexor?", and (3) "In the past 12 months, did you take sleeping pills?" The first two questions were recoded into one variable to differentiate between those who used tranquilizers and/or antidepressants during the past year and those who did not.

2.3. Statistical Analyses. To meet the objectives of the study, we performed two sequential multiple linear regression analyses, one for men and one for women. The forced entry (enter) method was used since we had good theoretical reasons to include all the variables in each model simultaneously [42]. Analyses were performed using PASW (Predictive Analytics Software) Statistics 18. Correlations and crosstabulations between variables were first verified to ensure the absence of multicollinearity.

First, to assess the relationship between drinking profiles (independent categorical variable) and self-rated health (dependent continuous variable), we entered the drinking profiles in the first regression model. To verify the hypotheses, we focused on the following: (a) the proportion of variance explained by the drinking profiles $\left(R^{2}\right.$ value $)$ and (b) the comparison between frequent/moderate drinkers (the reference category) with other types of drinkers and nondrinkers regarding self-rated health. This was done using unstandardized coefficients with confidence intervals ( $95 \%$ CIs).

Secondly, to determine if and how this relationship is modified by demographic, psychosocial, and health-related variables (independent variables), we entered these control 
variables in the second regression model (the adjusted model). Here, we emphasized the following: (a) the proportion of variance explained by the second model compared with the first one ( $R^{2}$ model 2 minus $R^{2}$ model 1 ) and (b) the comparison between frequent/moderate drinkers and other types of drinkers and nondrinkers regarding self-rated health when adjusting for demographic, psychosocial, and healthrelated variables. Again, this was done using unstandardized coefficients with CIs.

\section{Results}

3.1. Drinking Variables. The upper part of Table 1 shows the sample's drinking characteristics by gender. Three quarters of men $(73.9 \%)$ and $65.4 \%$ of women are current drinkers. The majority of men drink weekly (61.6\%) whereas the majority of women drink monthly or less $(60.1 \%)$. Binge drinking had occurred less than once a month or never during the past year among $77.8 \%$ of men and $94.7 \%$ of women. However, $13.1 \%$ of men report binge drinking 1-3 days a month and $9.2 \%$ on a weekly basis. For the quantity of drinking, $72.2 \%$ of men and $90.9 \%$ of women usually consume 1-2 drinks per drinking day, whereas $19.5 \%$ of men and $8.3 \%$ of women take 3-4 drinks per drinking day. Among men, $8.3 \%$ usually consume 5 drinks or more per drinking day whereas among women this proportion is very low $(0.8 \%)$.

The distribution of respondents (rates) for each category of the drinking profiles typology is presented in the lower portion of Table 1 . The lifetime abstainers' category includes $6 \%$ of men and $14.6 \%$ of women. About twenty percent of men and women are former drinkers. Infrequent drinkers have the highest rate among both men and women, respectively, $28.8 \%$ and $39.4 \%$. A quarter of the men and $21.5 \%$ of women are frequent/moderate drinkers whereas $19.5 \%$ of men $4.2 \%$ of women are frequent/nonmoderate drinkers.

3.2. Demographic, Psychosocial, and Health-Related Variables. Table 2 shows the demographic, psychosocial, and healthrelated characteristics of the sample by gender. For marital status, the majority of men (72.5\%) and women $(57.2 \%)$ are married/partnered. Twenty percent of men and $35.4 \%$ of women are divorced/separated/widowed and around $7 \%$ of men and women are single/never married. Concerning education, about half the men and half the women have a secondary education or less whereas the other half have some post-secondary studies or a university degree. As for employment status, almost half the men are working for pay and the other half are retired. Among women, half are retired and the other half are working for pay (31.8\%) and "other" $(12.9 \%)$.

The majority of men (77\%) and women $(89.9 \%)$ have at least one person to confide in and around forty percent of men $(39.4 \%)$ and women $(43.8 \%)$ are members of voluntary organizations or associations. On average, men and women think they are in good to very good psychological and physical health (means ranging between 2 and 2.5). The BMI indicates that $0.6 \%$ of men and $2.2 \%$ of women are underweight, $29.1 \%$ and $43.7 \%$ are in the normal weight
TABLE 1: Drinking characteristics of men and women, 55-74 years of age $(n=3,613)$.

\begin{tabular}{lcc}
\hline & Men & Women \\
Drinking variables & $n=1,473$ & $n=2,140$ \\
& $(\%)$ & $(\%)$ \\
\hline Current drinkers & 73.9 & 65.4 \\
Frequency of drinking & $n=1,082$ & $n=1,389$ \\
Less than once a month & 16.5 & 32.0 \\
1-3 days per month & 21.9 & 28.1 \\
1-2 days per week & 27.7 & 21.2 \\
3+ days per week & 33.9 & 18.6 \\
Frequency of binge drinking & $n=1,072$ & $n=1,395$ \\
Never & 55.8 & 84.2 \\
Less than once a month & 22.0 & 10.5 \\
1-3 days per month & 13.1 & 3.6 \\
1-2 days per week & 6.0 & 1.1 \\
3+ days per week & 3.2 & 0.6 \\
Quantity of drinking & $n=1,063$ & $n=1,385$ \\
1-2 drinks per drinking day & 72.2 & 90.9 \\
3-4 drinks per drinking day & 19.5 & 8.3 \\
5+ drinks per drinking day & 8.3 & 0.8 \\
Drinking profiles & $n=1,443$ & $n=2,121$ \\
Lifetime abstainers & 6.0 & 14.6 \\
Former drinkers & 20.7 & 20.3 \\
Frequent/moderate drinkers & 25.1 & 21.5 \\
Frequent/nonmoderate drinkers & 19.5 & 4.2 \\
Infrequent drinkers & 28.8 & 39.4 \\
\hline
\end{tabular}

Note. The numbers $(n)$ vary slightly because of missing responses.

range, $51.2 \%$ and $35.1 \%$ are overweight, and $19 \%$ of men and women are obese. Cigarette smoking status shows that $29.5 \%$ of men and $45.7 \%$ of women never smoked, whereas $48.1 \%$ of men and $34.1 \%$ of women smoked prior to the last 12 months and about $20 \%$ of men and women smoked during the last year. Among men, 9.8\% are tranquilizer/antidepressant users and $9.5 \%$ are sleeping pill users, and that holds true for, respectively, $15.6 \%$ and $12 \%$ of women.

3.3. Regression Analyses. Results of the regression analyses for men and women are presented in Tables 3 and 4, respectively. First models indicate that drinking profiles accounted for $3.3 \%$ (men: $R^{2}=0.033$ ) and $4.8 \%$ (women: $R^{2}=0.048$ ) of the variation in self-rated health. For both genders, compared with frequent/moderate drinkers, lifetime abstainers (men: 0.48, $p<0.01$; women: 0.60, $p<0.001$ ), former drinkers (men: 0.62, $p<0.001$; women: $0.75, p<0.001$ ), infrequent drinkers (men: $0.30, p<0.001$; women: $0.37, p<0.001$ ), and frequent/nonmoderate drinkers (men: $0.22, p<0.05$; women: $0.34, p<0.05$ ) all had higher scores on the self-rated health measure, meaning all of these groups had a worse selfrated health (as a reminder: $1=$ excellent to $5=$ poor). Thus, frequent/moderate drinkers reported a significantly better self-rated health compared with all the other types of drinkers and nondrinkers. 
TABLE 2: Demographic, psychosocial, and health-related characteristics (control variables) of men and women, $55-74$ years of age $(n=$ $3,613)$.

\begin{tabular}{|c|c|c|}
\hline & $\begin{array}{c}\text { Men } \\
n=1,473\end{array}$ & $\begin{array}{c}\text { Women } \\
n=2,140\end{array}$ \\
\hline \multicolumn{3}{|l|}{ Demographic variables } \\
\hline Marital status (\%) & $n=1,469$ & $n=2,131$ \\
\hline Married/partnered & 72.5 & 57.2 \\
\hline Divorced/separated/widowed & 19.9 & 35.4 \\
\hline Single/never married & 7.6 & 7.4 \\
\hline Education (\%) & $n=1,443$ & $n=2,094$ \\
\hline Less than secondary & 29.9 & 28.5 \\
\hline Secondary & 23.2 & 28.0 \\
\hline Some post-secondary studies & 20.4 & 24.9 \\
\hline University degree & 26.4 & 18.6 \\
\hline Employment status (\%) & $n=1,456$ & $n=2,101$ \\
\hline Working for pay & 45.9 & 31.8 \\
\hline Retired & 47.9 & 55.3 \\
\hline Other & 6.3 & 12.9 \\
\hline \multicolumn{3}{|l|}{ Psychosocial variables } \\
\hline \multirow[t]{2}{*}{ Having at least one confidant (\%) } & $n=1,441$ & $n=2,128$ \\
\hline & 77 & 89.9 \\
\hline \multirow[t]{2}{*}{ Member of voluntary org./ass. (\%) } & $n=1,467$ & $n=2,134$ \\
\hline & 39.4 & 43.8 \\
\hline Self-rated psychological health ${ }^{a}$ & $n=1,464$ & $n=2,129$ \\
\hline$(1=$ excellent to $5=$ poor $)$ & $\begin{aligned} \mathrm{M} & =2.11 \\
(\mathrm{SD} & =0.96)\end{aligned}$ & $\begin{array}{c}\mathrm{M}=2.23 \\
(\mathrm{SD}=1.01)\end{array}$ \\
\hline \multicolumn{3}{|l|}{ Health-related variables } \\
\hline Self-rated physical health ${ }^{\mathrm{a}}$ & $n=1,466$ & $n=2,135$ \\
\hline$(1=$ excellent to $5=$ poor $)$ & $\begin{array}{c}M=2.37 \\
(\mathrm{SD}=1.19)\end{array}$ & $\begin{array}{c}\mathrm{M}=2.46 \\
(\mathrm{SD}=1.17)\end{array}$ \\
\hline Body mass index (BMI) (\%) & $n=1,461$ & $n=2,044$ \\
\hline Underweight & 0.6 & 2.2 \\
\hline Normal weight & 29.1 & 43.7 \\
\hline Overweight & 51.2 & 35.1 \\
\hline Obese & 19.1 & 19.0 \\
\hline Cigarette smoking status (\%) & $n=1,473$ & $n=2,140$ \\
\hline Never smoked & 29.5 & 45.7 \\
\hline Smoked prior to last 12 months & 48.1 & 34.1 \\
\hline Smoked within last 12 months & 22.3 & 20.2 \\
\hline \multirow[t]{2}{*}{ Tranquilizer/antidep. use (\%) } & $n=1,473$ & $n=2,140$ \\
\hline & 9.8 & 15.6 \\
\hline \multirow[t]{2}{*}{ Sleeping pill use (\%) } & $n=1,473$ & $n=2,139$ \\
\hline & 9.5 & 12 \\
\hline
\end{tabular}

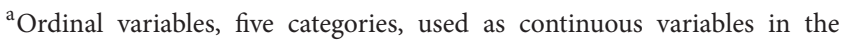
analyses.

The demographic, psychosocial, and health-related variables in the second (adjusted) models explained a large amount of the variation in self-rated health: $27.2 \%\left(R^{2}=\right.$ $0.305 ; 30.5 \%$ model 2 minus $3.3 \%$ model 1 ) among men and
$28.1 \%\left(R^{2}=0.329 ; 32.9 \%\right.$ minus $\left.4.8 \%\right)$ among women. These second model variables explained a significantly greater proportion of the variance in self-rated health compared with drinking profiles in the first model. Lifetime abstainers (men: 0.29, $p<0.05$; women: 0.33, $p<0.001$ ) and former drinkers (men: $0.25, p<0.01$; women: $0.41, p<0.001$ ) were still likely to perceive their health as worse compared with frequent/moderate drinkers in the second model, but the difference between frequent/moderate drinkers and frequent/nonmoderate drinkers became not significant. The difference between frequent/moderate drinkers and infrequent drinkers also became not significant among men whereas it remained significant among women $(0.20, p<0.01)$.

\section{Discussion}

As expected, our results showed that frequent/moderate drinkers were likely to report a better self-rated health compared with other types of drinkers (frequent/nonmoderate and infrequent drinkers) and nondrinkers (lifetime abstainers and former drinkers). When the demographic, psychosocial, and health-related (control) variables were considered in the regression models, frequent/moderate drinkers were still more likely to report a better self-rated health compared with nondrinkers. However, differences between frequent/moderate drinkers and other types of drinkers disappeared, except for infrequent female drinkers who still reported worse self-rated health. Infrequent female drinkers may drink small quantities of alcohol that places them at the "nondrinking" level of lifetime abstainers and former drinkers.

These findings add to the very limited literature on selfrated health and alcohol among older adults. Our results are generally consistent with those from past cross-sectional studies among the adult population (as opposed to the older adults' population) from other alcohol drinking countries, which found a J-shaped relationship between alcohol consumption and suboptimal (poor) self-rated health [43-48] or an L-shaped relationship; that is, the higher the consumption of alcohol, the lower the presence of suboptimal health [49, 50]. Our results also corroborate those from a recent study that evaluated a sample of older adults specifically [51]. This cross-sectional and longitudinal study by Frisher and collaborators (2015) examined, among a representative sample of the England population aged 50 years and older, the association between drinking profiles (quantity and frequency) and selfrated health adjusting for gender, age, wealth, social class, education, household composition, smoking, and body mass index. Their results showed that the prevalence of poor selfrated health was highest among nondrinkers, that none of the drinking profiles were associated with poor self-rated health, and that drinking profiles did not predict self-rated health at ten-year follow-up. Also similarly to our results, they found that demographic variables were associated with selfrated health but did not substantially change the association between drinking profiles and self-rated health.

Our results suggest that drinking is related to a better self-rated health compared with nondrinking regardless of the drinking profile. A probable reason why we did not 
TABLE 3: Regression analysis of self-rated health among men, 55-74 years of age $(n=1,424)$.

\begin{tabular}{|c|c|c|c|}
\hline \multirow{2}{*}{ Variables } & \multirow{2}{*}{$B$} & \multicolumn{2}{|c|}{ 95\% confidence intervals } \\
\hline & & Lower & Upper \\
\hline \multicolumn{4}{|l|}{ Model 1: $R^{2}=0.033$} \\
\hline \multicolumn{4}{|l|}{ Drinking profiles } \\
\hline Lifetime abst. versus freq./mod. drinkers & $0.48^{* *}$ & 0.20 & 0.75 \\
\hline Former drinkers versus freq./mod. drinkers & $0.62^{* * *}$ & 0.44 & 0.80 \\
\hline Infreq. drinkers versus freq./mod. drinkers & $0.30^{* * *}$ & 0.13 & 0.46 \\
\hline Freq./nonmod. drinkers versus freq./mod. drinkers & $0.22^{*}$ & 0.04 & 0.40 \\
\hline \multicolumn{4}{|l|}{ Model 2 (including control variables): $R^{2}=0.305$} \\
\hline \multicolumn{4}{|l|}{ Drinking profiles } \\
\hline Lifetime abst. versus freq./mod. drinkers & $0.29^{*}$ & 0.04 & 0.53 \\
\hline Former drinkers versus freq./mod. drinkers & $0.25^{* *}$ & 0.09 & 0.41 \\
\hline Infreq. drinkers versus freq./mod. drinkers & 0.10 & -0.04 & 0.24 \\
\hline Freq./nonmod. drinkers versus freq./mod. drinkers & 0.04 & -0.12 & 0.20 \\
\hline \multicolumn{4}{|l|}{ Demographic variables } \\
\hline Age & 0.00 & -0.01 & 0.01 \\
\hline Divorced/separated/widowed versus married/partnered & -0.04 & -0.17 & 0.10 \\
\hline Single/never married versus married/partnered & -0.11 & -0.31 & 0.10 \\
\hline Secondary versus less than secondary & $-0.15^{*}$ & -0.30 & -0.01 \\
\hline Some post-secondary versus less than secondary & $-0.17^{*}$ & -0.32 & -0.01 \\
\hline University degree versus less than secondary & $-0.25^{* *}$ & -0.40 & -0.10 \\
\hline Retired versus working for pay & $0.22^{* *}$ & 0.09 & 0.35 \\
\hline Other versus working for pay & $0.78^{* * *}$ & 0.54 & 1.01 \\
\hline \multicolumn{4}{|l|}{ Psychosocial variables } \\
\hline Having at least one confidant & -0.06 & -0.19 & 0.06 \\
\hline Member of voluntary org./ass. & -0.07 & -0.18 & 0.04 \\
\hline Self-rated psychological health & $0.48^{* * *}$ & 0.43 & 0.54 \\
\hline$(1=$ excellent to $5=$ poor $)$ & & & \\
\hline \multicolumn{4}{|l|}{ Health-related variables } \\
\hline Underweight versus normal weight & 0.40 & -0.30 & 1.12 \\
\hline Overweight versus normal weight & $0.14^{*}$ & 0.02 & 0.26 \\
\hline Obese versus normal weight & $0.52^{* * *}$ & 0.37 & 0.68 \\
\hline Smoked prior to last 12 months versus never smoked & 0.08 & -0.05 & 0.20 \\
\hline Smoked within last 12 months versus never smoked & $0.31^{* * *}$ & 0.16 & 0.46 \\
\hline Tranquilizer/antidep. use & 0.13 & -0.06 & 0.32 \\
\hline Sleeping pill use & $0.21^{*}$ & 0.01 & 0.40 \\
\hline
\end{tabular}

${ }^{*} p<0.05,{ }^{* *} p<0.01,{ }^{* * *} p<0.001$.

Note. $B$ : unstandardized coefficients. Higher scores mean worse self-rated health.

find any differences between frequent/moderate drinkers and other types of drinkers regarding self-rated health could be that the older adults from our sample did not report binge drinking frequently (i.e., frequency of having 5 drinks or more per drinking occasion) and were, in majority, very light to moderate drinkers. Another possible explanation could be that important lifestyle factors, which were not measured in our study, could have made a difference between drinking profiles regarding self-rated health, such as physical exercise and dietary habits. This would correspond to the well-known health risk factors (tobacco use, physical inactivity, unhealthy diet, and harmful use of alcohol) [52] and to the findings from a recent meta-analysis: compared with individuals with unhealthy lifestyle behaviors, such as abstaining from alcohol or excessive drinking, smoking, not exercising, having an unhealthy diet and being obese, individuals with at least four healthy lifestyle behaviors, including moderate drinking, not smoking, eating healthily (Mediterranean diet or regular eating of fruit/vegetables), exercising on a regular basis, and maintaining a normal weight, had a reduction in all-cause mortality risk by $66 \%$ [53]. Finally, we cannot exclude that our results might reflect the positive biological effect of alcohol on 
TABLE 4: Regression analysis of self-rated health among women, 55-74 years of age $(n=2,106)$.

\begin{tabular}{|c|c|c|c|}
\hline \multirow{2}{*}{ Variables } & \multirow{2}{*}{$B$} & \multicolumn{2}{|c|}{$95 \%$ confidence intervals } \\
\hline & & Lower & Upper \\
\hline \multicolumn{4}{|l|}{ Model 1: $R^{2}=0.048$} \\
\hline \multicolumn{4}{|l|}{ Drinking profiles } \\
\hline Lifetime abst. versus freq./mod. drinkers & $0.60^{* * *}$ & 0.43 & 0.76 \\
\hline Former drinkers versus freq./mod. drinkers & $0.75^{* * *}$ & 0.60 & 0.90 \\
\hline Infreq. drinkers versus freq./mod. drinkers & $0.37^{* * *}$ & 0.24 & 0.50 \\
\hline Freq./nonmod. drinkers versus freq./mod. drinkers & $0.34^{*}$ & 0.08 & 0.60 \\
\hline \multicolumn{4}{|l|}{ Model 2 (including control variables): $R^{2}=0.329$} \\
\hline \multicolumn{4}{|l|}{ Drinking profiles } \\
\hline Lifetime abst. versus freq./mod. drinkers & $0.33^{* * *}$ & 0.18 & 0.48 \\
\hline Former drinkers versus freq./mod. drinkers & $0.41^{* * *}$ & 0.28 & 0.54 \\
\hline Infreq. drinkers versus freq./mod. drinkers & $0.20^{* *}$ & 0.09 & 0.31 \\
\hline Freq./nonmod. drinkers versus freq./mod. drinkers & 0.09 & -0.13 & 0.32 \\
\hline \multicolumn{4}{|l|}{ Demographic variables } \\
\hline Age & 0.00 & -0.01 & 0.01 \\
\hline Divorced/separated/widowed versus married/partnered & 0.01 & -0.08 & 0.10 \\
\hline Single/never married versus married/partnered & 0.08 & -0.08 & 0.24 \\
\hline Secondary versus less than secondary & $-0.12^{*}$ & -0.23 & -0.01 \\
\hline Some post-secondary versus less than secondary & -0.07 & -0.19 & 0.05 \\
\hline University degree versus less than secondary & $-0.17^{*}$ & -0.31 & -0.04 \\
\hline Retired versus working for pay & $0.16^{* *}$ & 0.05 & 0.27 \\
\hline Other versus working for pay & $0.48^{* * *}$ & 0.34 & 0.62 \\
\hline \multicolumn{4}{|l|}{ Psychosocial variables } \\
\hline Having at least one confidant & -0.09 & -0.23 & 0.05 \\
\hline Member of voluntary org./ass. & -0.03 & -0.11 & 0.06 \\
\hline Self-rated psychological health & $0.45^{* * *}$ & 0.41 & 0.50 \\
\hline$(1=$ excellent to $5=$ poor $)$ & & & \\
\hline \multicolumn{4}{|l|}{ Health-related variables } \\
\hline Underweight versus normal weight & 0.10 & -0.20 & 0.41 \\
\hline Overweight versus normal weight & $0.12^{* *}$ & 0.03 & 0.22 \\
\hline Obese versus normal weight & $0.42^{* * *}$ & 0.30 & 0.54 \\
\hline Smoked prior to last 12 months versus never smoked & 0.08 & -0.01 & 0.18 \\
\hline Smoked within last 12 months versus never smoked & $0.17^{* *}$ & 0.05 & 0.28 \\
\hline Tranquilizer/antidep. use & $0.32^{* * *}$ & 0.19 & 0.44 \\
\hline Sleeping pill use & $0.26^{* * *}$ & 0.12 & 0.39 \\
\hline
\end{tabular}

${ }^{*} p<0.05,{ }^{* *} p<0.01,{ }^{* * *} p<0.001$.

Note. $B$ : unstandardized coefficients. Higher scores mean worse self-rated health.

health. More data are needed to provide definitive evidence and clarify which explanation is the most plausible.

When distilling the vast literature on the subject, it makes sense that the benefits of drinking are conditional on other health practices and/or other life conditions. The relationship between alcohol and health requires taking into account the life-course drinking patterns and associated lifestyles factors [51].

This study has several limitations. First, the crosssectional design makes causal interpretations impossible. The drinking profiles and other determinants of health were significantly associated with self-rated health, but the direction of this association is unknown. Second, the subsample used in this study was not a representative sample of older adults in Canada, thus limiting the ability to generalize our results. Third, we decided to exclude respondents aged 75 years and older from the analyses because there were too few of them in the sample. However, with the increasing longevity worldwide, more research is needed to better understand these older individuals' alcohol use. Fourth, self-reported 
data may have biases in recall and reporting. Memory errors, difficulties in the assessment of alcohol content, and the potential stigma associated with alcohol consumption may have led to an underestimation of drinking [54-56]. Fifth, although the self-rated health measure has been shown to be strongly correlated with actual health status [36-39], it does not assess physical health directly and empirically. Results have to be interpreted cautiously because they apply to the respondents' subjective perception of health. A final limitation of this study is its inability to classify former drinkers by their reasons for stopping drinking. This is due to the data collection: the survey was designed to ask only $50 \%$ of lifetime abstainers and former drinkers to provide reasons for abstaining. The number of cases in each category would have been too small to conduct analyses.

\section{Conclusions}

In this study among older adults, no evidence indicates that drinking alcohol is associated with poor self-rated health. Our results concur with comparable studies in other Western countries suggesting that alcohol drinking in old age, as is the case with most respondents in this study, may be a marker of good health. Nevertheless, the relationship is complex and other factors, both past and present in the life cycle, mediate this relationship. To avoid the oversimplification of the association between alcohol and health, the building of healthpredicting models for mature and old adults will require integrated research that will examine drinking profiles and other determinants of health.

\section{Disclosure}

This research was conducted as part of the GENACIS project, a collaborative multinational project led by Sharon Wilsnack and affiliated with the Kettil Bruun Society for Social and Epidemiological Research on Alcohol.

\section{Conflict of Interests}

The authors declare that there is no conflict of interests regarding the publication of this paper.

\section{Acknowledgments}

The Canadian data (GENACIS-Canada) reported in this paper were supported by a grant from the Canadian Institutes of Health Research (CIHR) (Graham K. (Principle Investigator) and Demers A. (Co-Principle Investigator)). The first author received funding from the Frederick Banting and Charles Best Canada Graduate Scholarship Doctoral Award (Canadian Institutes of Health Research) and the Centre Dollard-Cormier-Institut Universitaire sur les Dépendances.

\section{References}

[1] World Health Organization, World Report on Ageing and Health, World Health Organization, 2015, http://www.who.int/ kobe_centre/mediacentre/world_report_on_ageing_and_health_ eng.pdf.
[2] M. Dufour and R. K. Fuller, "Alcohol in the elderly," Annual Review of Medicine, vol. 46, pp. 123-132, 1995.

[3] A. A. Moore, E. J. Whiteman, and K. T. Ward, "Risks of combined alcohol/medication use in older adults," The American Journal Geriatric Pharmacotherapy, vol. 5, no. 1, pp. 64-74, 2007.

[4] G. Whelan, "Alcohol: a much neglected risk factor in elderly mental disorders," Current Opinion in Psychiatry, vol. 16, no. 6, pp. 609-614, 2003.

[5] V. Bagnardi, A. Zambon, P. Quatto, and G. Corrao, "Flexible meta-regression functions for modeling aggregate doseresponse data, with an application to alcohol and mortality," American Journal of Epidemiology, vol. 159, no. 11, pp. 1077-1086, 2004.

[6] G. Corrao, L. Rubbiati, V. Bagnardi, A. Zambon, and K. Poikolainen, "Alcohol and coronary heart disease: a meta-analysis," Addiction, vol. 95, no. 10, pp. 1505-1523, 2000.

[7] A. Di Castelnuovo, S. Costanzo, V. Bagnardi, M. B. Donati, L. Iacoviello, and G. De Gaetano, "Alcohol dosing and total mortality in men and women: an updated meta-analysis of 34 prospective studies," Archives of Internal Medicine, vol. 166, no. 22, pp. 2437-2445, 2006.

[8] A. L. Klatsky, "Moderate drinking and reduced risk of heart disease," Alcohol Research \& Health, vol. 23, no. 1, pp. 15-23, 1999.

[9] A. Poli, F. Marangoni, A. Avogaro et al., "Moderate alcohol use and health: a consensus document," Nutrition, Metabolism and Cardiovascular Diseases, vol. 23, no. 6, pp. 487-504, 2013.

[10] P. E. Ronksley, S. E. Brien, B. J. Turner, K. J. Mukamal, and W. A. Ghali, "Association of alcohol consumption with selected cardiovascular disease outcomes: a systematic review and metaanalysis," British Medical Journal, vol. 342, article d671, pp. 1-13, 2011.

[11] P. Butt, D. Beirness, F. Cesa, L. Gliksman, C. Paradis, and T. Stockwell, Alcohol and Health in Canada: A Summary of Evidence and Guidelines for Low-Risk Drinking, Canadian Centre on Substance Abuse, Ottawa, Canada, 2011.

[12] A. F. R. Dixon, J. B. Dixon, and P. E. O’Brien, “Cardiovascular benefit of light to moderate alcohol consumption," Australian Family Physician, vol. 32, no. 8, pp. 649-652, 2003.

[13] R. C. Ellison, "Balancing the risks and benefits of moderate drinking," Annals of the New York Academy of Sciences, vol. 957, pp. 1-6, 2002.

[14] U. A. Hvidtfeldt, J. S. Tolstrup, M. U. Jakobsen et al., "Alcohol intake and risk of coronary heart disease in younger, middleaged, and older adults," Circulation, vol. 121, no. 14, pp. 1589$1597,2010$.

[15] J. H. O’Keefe, S. K. Bhatti, A. Bajwa, J. J. DiNicolantonio, and C. J. Lavie, "Alcohol and cardiovascular health: the dose makes the poison...or the remedy," Mayo Clinic Proceedings, vol. 89, no. 3, pp. 382-393, 2014.

[16] J. Rehm, C. T. Sempos, and M. Trevisan, "Average volume of alcohol consumption, patterns of drinking and risk of coronary heart disease-a review," Journal of Cardiovascular Risk, vol. 10, no. 1, pp. 15-20, 2003.

[17] J. R. Emberson and D. A. Bennett, "Effect of alcohol on risk of coronary heart disease and stroke: causality, bias, or a bit of both?" Vascular Health and Risk Management, vol. 2, no. 3, pp. 239-249, 2006.

[18] K. M. Fillmore, J. M. Golding, K. L. Graves et al., "Alcohol consumption and mortality. I. Characteristics of drinking groups," Addiction, vol. 93, no. 2, pp. 183-203, 1998. 
[19] K. M. Fillmore, W. C. Kerr, T. Stockwell, T. Chikritzhs, and A. Bostrom, "Moderate alcohol use and reduced mortality risk: systematic error in prospective studies," Addiction Research and Theory, vol. 14, no. 2, pp. 101-132, 2006.

[20] R. Jackson, J. Broad, J. Connor, and S. Wells, "Alcohol and ischaemic heart disease: probably no free lunch," The Lancet, vol. 366, no. 9501, pp. 1911-1912, 2005.

[21] D. J. Pittman, "What do we know about beneficial consequences of moderate alcohol consumption on social and physical wellbeing? A critical review of the recent literature," Contemporary Drug Problems, vol. 23, pp. 389-406, 1996.

[22] K. Svärdsudd, "Moderate alcohol consumption and cardiovascular disease: is there evidence for a preventive effect?" Alcoholism: Clinical and Experimental Research, vol. 22, supplement 7, pp. S307-S314, 1998.

[23] B. Fagrell, U. De Faire, S. Bondy et al., "The effects of light to moderate drinking on cardiovascular diseases," Journal of Internal Medicine, vol. 246, no. 4, pp. 331-340, 1999.

[24] M. J. Ashley, R. Ferrence, R. Room, S. Bondy, J. Rehm, and E. Single, "Moderate drinking and health: implications of recent evidence," Canadian Family Physician, vol. 43, pp. 687-694, 1997.

[25] T. M. Caldwell, B. Rodgers, A. F. Jorm et al., "Patterns of association between alcohol consumption and symptoms of depression and anxiety in young adults," Addiction, vol. 97, no. 5, pp. 583-594, 2002.

[26] T. S. Naimi, D. W. Brown, R. D. Brewer et al., "Cardiovascular risk factors and confounders among nondrinking and moderate-drinking U.S. adults," American Journal of Preventive Medicine, vol. 28, no. 4, pp. 369-373, 2005.

[27] B. Rodgers, A. E. Korten, A. F. Jorm, H. Christensen, S. Henderson, and P. A. Jacomb, "Risk factors for depression and anxiety in abstainers, moderate drinkers and heavy drinkers," Addiction, vol. 95, no. 12, pp. 1833-1845, 2000.

[28] M. E. Hilton, "Abstention in the general population of the USA," British Journal of Addiction, vol. 81, no. 1, pp. 95-112, 1986.

[29] G. Knupfer and R. Room, "Age, sex, and social class as factors in amount of drinking in a metropolitan community," Social Problems, vol. 12, pp. 224-240, 1964.

[30] M. J. Thun, R. Peto, A. D. Lopez et al., "Alcohol consumption and mortality among middle-aged and elderly U.S. adults," The New England Journal of Medicine, vol. 337, no. 24, pp. 1705-1714, 1997.

[31] J. G. Wallace, "Drinkers and abstainers in Norway: a national survey," Quarterly Journal of Studies on Alcohol, vol. 6, supplement 6, pp. 129-151, 1972.

[32] O.-J. Skog, "The J-curve, causality and public health," Addiction, vol. 90, no. 4, pp. 490-492, 1995.

[33] N. E. Adler, T. Boyce, M. A. Chesney et al., "Socioeconomic status and health: the challenge of the gradient," American Psychologist, vol. 49, no. 1, pp. 15-24, 1994.

[34] K. M. Fillmore, W. C. Kerr, T. Stockwell, T. Chikritzhs, and A. Bostrom, "Has alcohol been proven to be protective against coronary heart disease?" Addiction Research and Theory, vol. 15, no. 1, pp. 35-46, 2007.

[35] K. Graham, A. Demers, L. Nadeau et al., A Multinational Perspective on Gender, Alcohol and Health: GENACIS Canada, a National Survey to Be Done in Collaboration with the International GENACIS Project, Canadian Institutes of Health, 2003.

[36] M. Bergner, R. A. Bobbitt, W. E. Pollard, D. P. Martin, and B. S. Gilson, "The sickness impact profile: validation of a health status measure," Medical Care, vol. 14, no. 1, pp. 57-67, 1976.
[37] J. E. Brazier, R. Harper, N. M. B. Jones et al., "Validating the SF-36 health survey questionnaire: new outcome measure for primary care," British Medical Journal, vol. 305, no. 6846, pp. 160-164, 1992.

[38] E. L. Idler and R. J. Angel, "Self-rated health and mortality in the NHANES-I epidemiologic follow-up study," American Journal of Public Health, vol. 80, no. 4, pp. 446-452, 1990.

[39] R. G. Laforge, G. D. Williams, T. C. Harford, and D. A. Parker, "Alcoholic beverage type, recall period effects and functional disability: evidence from the 1983 NHIS," Drug and Alcohol Dependence, vol. 25, no. 3, pp. 257-272, 1990.

[40] M. Pinquart, "Correlates of subjective health in older adults: a meta-analysis," Psychology and Aging, vol. 16, no. 3, pp. 414-426, 2001.

[41] World Health Organization, BMI Classification, World Health Organization, 2011, http://apps.who.int/bmi/index.jsp?introPage =intro_3.html.

[42] A. Field, Discovering Statistics Using SPSS for Windows: Advanced Techniques for the Beginner, Sage, London, UK, 2000.

[43] M. Groønbæk, E. L. Mortensen, K. Mygind et al., "Beer, wine, spirits and subjective health," Journal of Epidemiology and Community Health, vol. 53, no. 11, pp. 721-724, 1999.

[44] K. Poikolainen and E. Vartiainen, "Wine and good subjective health," American Journal of Epidemiology, vol. 150, no. 1, pp. 47-50, 1999.

[45] K. Poikolainen, E. Vartiainen, and H. J. Korhonen, "Alcohol intake and subjective health," American Journal of Epidemiology, vol. 144, no. 4, pp. 346-350, 1996.

[46] B. San José, H. van de Mheen, J. A. M. van Oers, J. P. Mackenbach, and H. F. L. Garretsen, "The U-shaped curve: various health measures and alcohol drinking patterns," Journal of Studies on Alcohol, vol. 60, no. 6, pp. 725-731, 1999.

[47] H. Theobald, S.-E. Johansson, and P. Engfeldt, "Influence of different types of alcoholic beverages on self-reported health status," Alcohol and Alcoholism, vol. 38, no. 6, pp. 583-588, 2003.

[48] A. P. Van Dijk, J. Toet, and J. E. E. Verdurmen, "The relationship between health-related quality of life and two measures of alcohol consumption," Journal of Studies on Alcohol, vol. 65, no. 2, pp. 241-249, 2004.

[49] P. Guallar-Castillón, F. Rodríguez-Artalejo, L. D. Gañán, J. R. B. Banegas, P. L. Urdinguio, and R. H. Cabrera, "Consumption of alcoholic beverages and subjective health in Spain," Journal of Epidemiology and Community Health, vol. 55, no. 9, pp. 648652, 2001.

[50] J. L. Valencia-Martín, I. Galán, and F. Rodríguez-Artalejo, "Alcohol and self-rated health in a Mediterranean country: the role of average volume, drinking pattern, and alcohol dependence," Alcoholism: Clinical and Experimental Research, vol. 33, no. 2, pp. 240-246, 2009.

[51] M. Frisher, M. Mendonça, N. Shelton, H. Pikhart, C. de Oliveira, and C. Holdsworth, "Is alcohol consumption in older adults associated with poor self-rated health? Cross-sectional and longitudinal analyses from the English Longitudinal Study of Ageing," BMC Public Health, vol. 15, pp. 703-711, 2015.

[52] World Health Organization, Risk Factors, World Health Organization, 2015, http://www.who.int/gho/ncd/risk_factors/en/.

[53] M. Loef and H. Walach, "The combined effects of healthy lifestyle behaviors on all cause mortality: a systematic review and meta-analysis," Preventive Medicine, vol. 55, no. 3, pp. $163-$ 170, 2012. 
[54] K. Graham, "Identifying and measuring alcohol abuse among the elderly: serious problems with existing instrumentation," Journal of Studies on Alcohol, vol. 47, no. 4, pp. 322-326, 1986.

[55] P. H. Lemmens, "The alcohol content of self report and 'standard' drinks," Addiction, vol. 89, no. 5, pp. 593-601, 1994.

[56] P. Lemmens, R. A. Knibbe, and F. Tan, "Weekly recall and diary estimates of alcohol consumption in a general population survey," Journal of Studies on Alcohol, vol. 49, no. 2, pp. 131-135, 1988. 


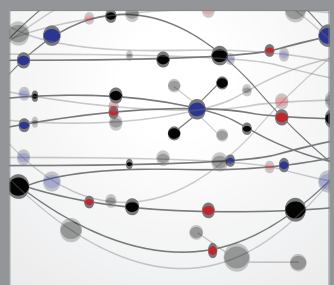

The Scientific World Journal
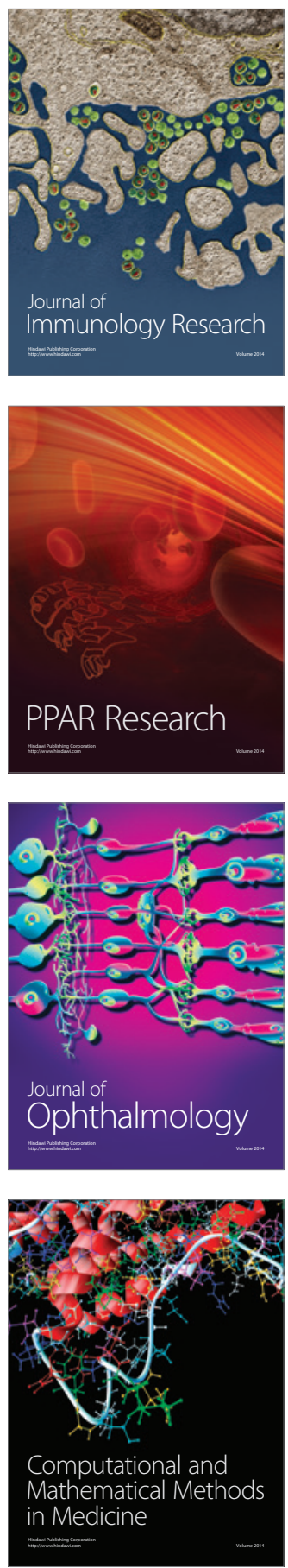

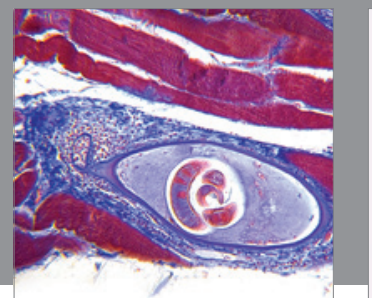

Gastroenterology

Research and Practice
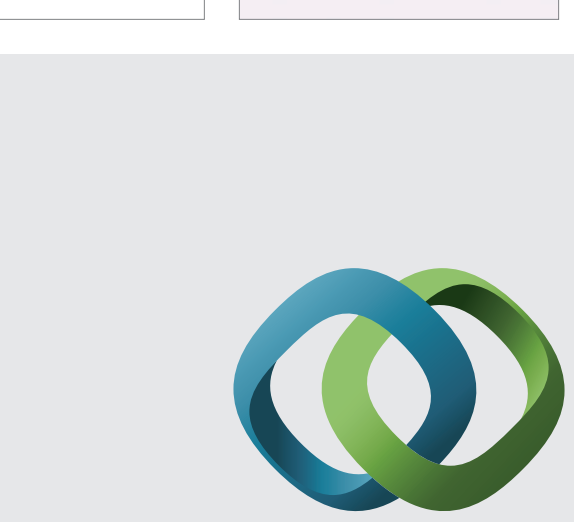

\section{Hindawi}

Submit your manuscripts at

http://www.hindawi.com
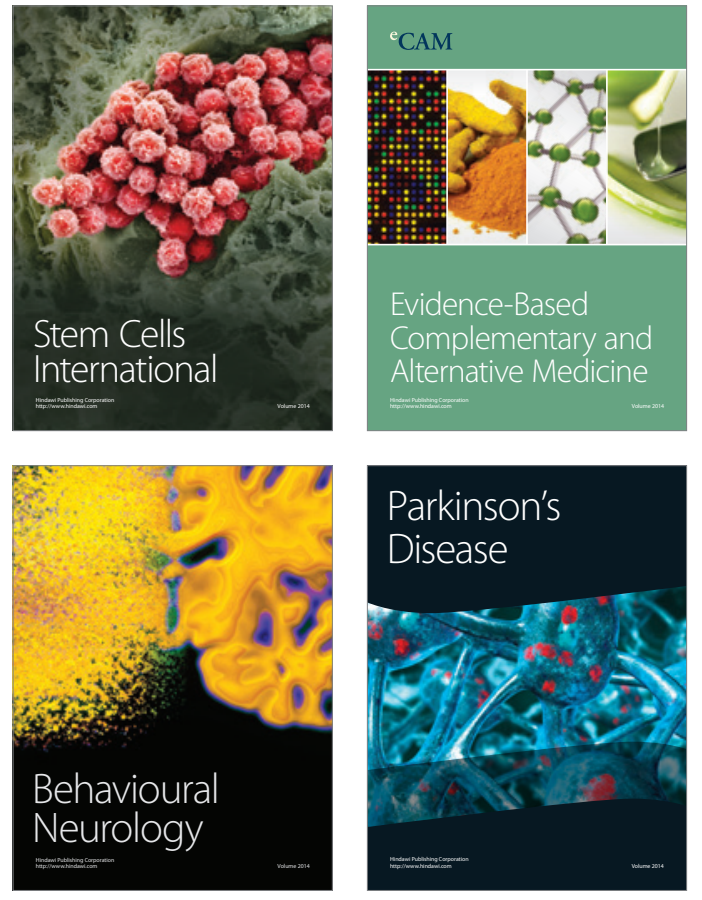
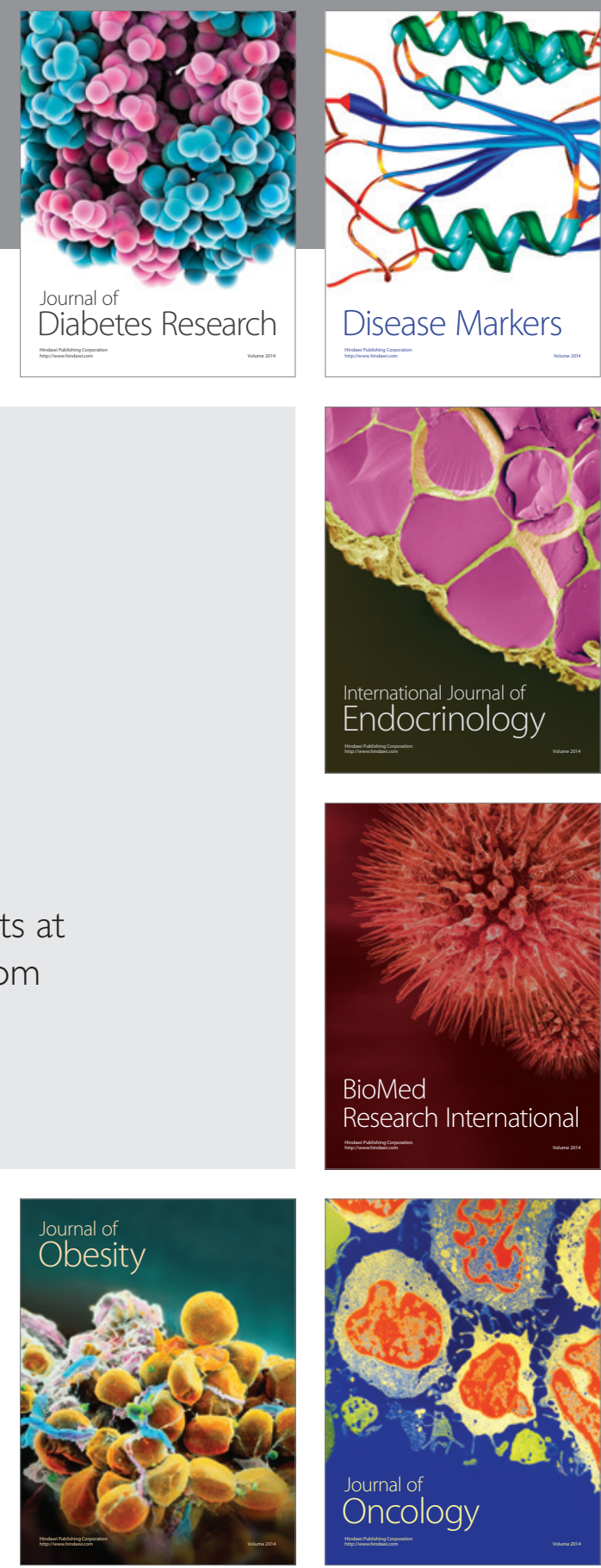

Disease Markers
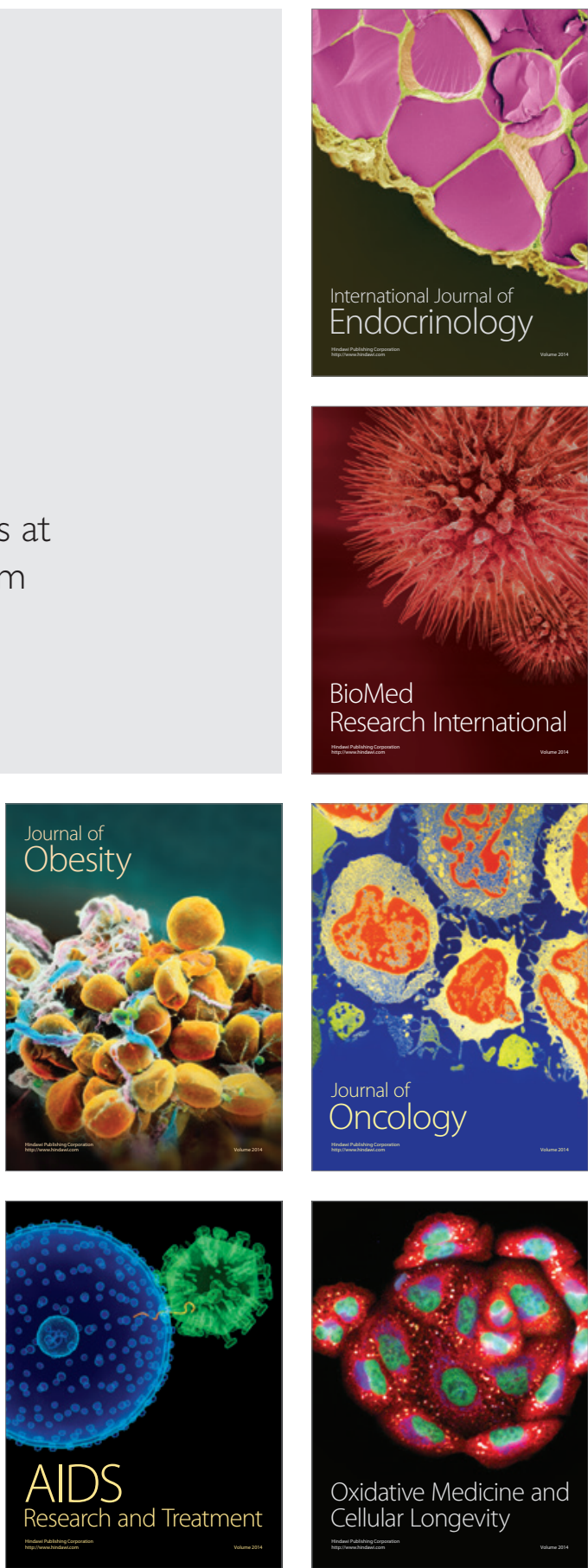